\title{
Effects of COVID-19 Pandemic on Behavior, Perception of Threat, Stress and Training Patterns of Olympic and Paralympic Athletes
}

María José Martínez-Patiño

University of Vigo

Francisco Javier Blas Lopez

University of Vigo

Michel Dubois

Sorbonne Université

Eric Vilain ( $\square$ evilain@email.gwu.edu)

Children's National Hospital https://orcid.org/0000-0002-5557-3709

Juan Pedro Fuentes-García

University of Extremadura

\section{Original Research Article}

Keywords: Olympic, Paralympic, psychological variables, perception of threat, stress.

Posted Date: July 13th, 2021

DOI: https://doi.org/10.21203/rs.3.rs-680241/v1

License: (c) (1) This work is licensed under a Creative Commons Attribution 4.0 International License. Read Full License 


\section{Abstract}

Objective Analyze the effect of the COVID-19 pandemic and its subsequent confinement on Olympic and Paralympic level athletes' behaviors, perception of threat, stress, state of mind and training patterns.

Methods All variables were modulated by gender, academic training, and sport discipline on a population composed of 447 Olympic ( $25.97 \pm 7.46$ years) and 64 Paralympic athletes $(28.44 \pm 10.50$ years $)$.

Results Most of the athletes recognize that their best athletic performance diminished due to the COVID-19 confinement but that will recover after the pandemic and its confinements. Almost half of the athletes declared they were more tired than normal and had difficulty sleeping, while more than half eat more or less as usual. Paralympic athletes report they felt more capable to cope with personal problems and feeling more frequently that life events where going well and less lonely during the confinement than the Olympians. The athletes from team sports disrupted their training routine more significantly than athletes of individual sports, seeing their athletic performance more affected. Athletes in individual sports felt more capable to cope with personal problems than athletes in team sports. Female athletes were significantly more tired and reported more difficulty sleeping than male.

Conclusions The situation caused by COVID-19 has had significant effects on the behavior, perception of threat, stress and training patterns of Olympic and Paralympic athletes facing the 2020 Tokyo Olympiad. It is necessary that sports institutions to reinforce mechanisms of help to athletes during future situations of confinement.

\section{Key Points}

COVID-19 pandemic resulted in modification in nutritional and training habits for the elite athletes. Perception of threat and stress were different between individual versus collective sports and between Olympic and Paralympic athletes.

\section{Introduction}

In December 2019, a novel coronavirus emerged in China, which posed an international public health emergency. This virus was named as the Severe Acute Respiratory Syndrome Coronavirus-2 (SARS-CoV-2) [1]. On March 11, 2020 the new coronavirus disease 2019 (COVID-19) was described as a pandemic by the World Health Organization (WHO) [2]. This pandemic is now a major global health issue, representing the most serious respiratory virus since the $1918 \mathrm{H} 1 \mathrm{~N} 1$ influenza pandemic[3].

On March 14, the Spanish Government declared a nationwide lockdown ordering people to stay at home [4] and approving the last extension of the state of alarm until June 21 [5]. As of this date, with no vaccine available and no herd immunity, the population must continue to maintain important safety standards for the sake of individual and collective health. On In the middle of the present study, September 13, 2020, there were 28,637,952 confirmed cases and 917,417 deaths worldwide [2] and Spain accumulates 12,113 confirmed cases and 636 deaths per million population. The lack of vaccines and the actual no population immunity due to the herd effect increase the feeling of danger and uncertainty in this health crisis [6].

The actual health crisis is a new threat that put the adaptive mechanisms of the human being, both physiologically and psychologically, through its paces. The human being is a highly adaptative organism, for this reason we developed in our evolution different physiological and psychological defence mechanism that allow us to overcome different eliciting contextual scenarios, but some of these phylogenetic defence system could produce non adaptative behaviour in current society and specially in exceptional situations [6]. In the current global home confinement situation due to the COVID-19 pandemic, most individuals are exposed to an unprecedented stressful situation of unknown duration, being a focus of stress, anxiety, fear and depression or disrupt sleep due to a negative appraisal of the situation and self-protection behaviours [7, 8].

In this line, one of the populations that could suffer more the confinement are athletes, especially professional ones. The Olympic and Paralympic athletes suffer an eliciting situation, since they have been preparing the Tokyo Olympiad for 4 years and their postponement is a more added stressor. This setback and the threat of the Coronavirus can cause the athlete to lose concentration, motivation and the desire to continue preparing for the Olympiad with the same energy as he did up until then. the perception of threat of this virus, the psychological profile of the athlete, as well as their psychological skills [9, 10], All this information would be fundamental to understand their stress response and to define professional interventions on these athletes so that they continue to prepare for the Olympiad at the highest level. Other factors as social support, academic level, gender or cultural differences could also modulate the behaviors in eliciting situations [11], making the knowledge of theses parameters and their relationships important factors in actual moments.

The confinement situation caused by COVID-19 has had significant effects on the perception of personal and professional threat of Olympic and Paralympic athletes facing the 2021 Tokyo Olympiad [12]. In the same vein, the study carried by Clemente-Suarez, Fuentes-Garcia, de la Vega, \& Martinez-Patiño [10] with Olympic out with Olympic and Paralympic athletes during confinement showed how they perceived how confinement negatively affects their workouts, even if it does not affect their performance, both approving the suspension of the Tokyo Olympics. Paralympic athletes perceived higher negative impact in their training and performance by the confinement than Olympic ones. Neuroticism and psychological inflexibility presented the greatest negative feelings and the perception that quarantine would negatively affect their sports performance. Faced with this same confinement situation generated by COVID-19, the study carried out by Fuentes-Garcia, Martinez-Patiño, Villafaina, \& Clemente-Suarez [13] on a sample of 450 chess players showed that a sample of accustomed chess players a long training durations, tournaments, and games, leading to mental, emotional, and physical stress, characteristics that could provide chess players a certain advantage in facing quarantine situations, showed that the amateur players presented a significantly higher level of social alarm than professional and high-performance players; while chess players with a higher academic level might have adapted their psychological profile to fit confinement situations and the worrying levels of physical inactivity. 
Then, the aim of this research was to analyse the effect of age, gender, academic training, participation, sport specialty and high options to participate in the Tokyo 2021 in the individual perceptions about COVID-19 crisis, psychological profile and training patterns.

\section{Methods}

This study was performed online using the surveymonkey internet platform (https://www.surveymonkey.com/). A correlational design with incidental sampling for convenience was used. During lockout, this methodology was the most appropriate for obtaining information.

\subsection{Participants}

In the present study were analyzed 511 Olympic and Paralympic athletes classified or in process to the Olympic Games in Tokyo 2021 ( $M=26.28$ years; $S D=$ 7.94). 447 Olympic ( $M=25.97$ years; $S D=7.46$ ) (Athletics: 42, Badminton: 1, Basketball: 30, Handball: 22, Baseball (softball): 16, Boxing: 12, Cycling: 14, Sport Climbing: 10, Fencing: 17, Soccer: 24, Gymnastics: 11, Golf: 20, Weightlifting: 12, Horse Riding: 3, Hockey: 47, Judo: 24, Karate: 3, Wrestling: 15, Swimming: 5 , Swimming Synchronized: 20, Modern Pentathlon: 5, Rowing: 3, Rugby: 11, Skateboarding: 3, Surfing: 11, Taekwondo: 17, Tennis: 3, Table Tennis: 5, Archery: 12, Olympic Shooting: 5, Triathlon: 7, Sailing: 5, Volleyball: 12$)$ and 64 Paralympic athletes ( $M=28.44$ years; $S D=10.50)($ Athletics: 35 , Basketball: 1 , Cycling: 6, Fencing, Weightlifting: 1, Horse Riding: 1, Judo: 1, Swimming: 1, Canoeing; 4, Taekwondo: 2, Tennis: 1, Table Tennis: 4, Archery: 1, Olympic Shooting: 2 , Triathlon: 4), gender: 257 male, 254 female. Before participation, experimental procedures were explained to all the participants who gave their voluntary written informed consent in accordance with the Declaration of Helsinki. All the procedures were approved by the Commission of Bioethics and Biosecurity of the University of Extremadura (Spain) (approval number: 57/2020).

The inclusion criteria used for the present research was that athletes were selectable by the corresponding sports federation with options to represent it in Tokyo 2021 Olympic or Paralympic Games.

\subsection{Procedure}

Due to the COVID-19 crisis and the limitation of free movement, an intentional opinion-type sampling type was used. The call to participate in the study was made through a link sent by the federations of the different sports [14]. The questionnaire was sent to 871 athletes: 678 Olympic athletes, answering 447 (66\%), and 193 Paralympic athletes, answering 64 (34\%). Athletes who completed the online survey gave their passive consent to participate at the time of participating in the research. This study was completely voluntary, and no personal data was requested through which the participants could be identified. Data collection lasted for 21 days (from September 2 to September 22, 2020).

Firstly, they filled the informed consent and then completed the following items:

Personal Information

- Age, gender, weight and height,

Psychological profile, by the following questionnaires

- Questionnaire on Perception of Threat from COVID-19. It is a 5-item questionnaire with a Likert-type scale from $0=$ ="It absolutely does not affect me" to 10 $=$ It gravely affects my life". The test provides an overall score on the representation of the illness. The higher the score is, the greater the perception of the illness as a threat (for example, "How much are you worried about being infected by the coronavirus (COVID-19)?" or "How much does infection by the coronavirus (COVID-19) affect you emotionally?" (That is, does it make you feel furious, afraid, angry or depressed?)". Perception Questionnaire (IPQ) for COVID-19 (Perez-Fuentes et al., 2020),

- Perceived Stress by Psychometric Properties of a European Spanish Version of the Perceived Stress Scale (PSS). It is a 10-item questionnaire with a Likert-type scale from $0=$ "Never" to $4=$ "Very often". The test is designed to measure the degree to which situations in one's life are appraised as stressful (for example, In the past month, how often have you been affected by an unexpected event?" or "In the past month, how often have you felt lack of control over important events in your life? (Remor, 2013).

Academic and training patterns information

- What is your level of education? Academic training (High school, Professional training, University training),

- At this moment, are you ranked or do you have high options to participate in the Tokyo 2021 Olympic or Paralympic? (Yes, No).

- What is your primary sport? Choose Olympics or Paralympics (_).

- On a scale of 1-4, how much was your training routine disrupted by COVID-19? (1 = "Not at all" to 4 = "Extremely disrupted").

- On a scale from 1-4, how much do you think that your athletic performance was affected by the confinement?

- How many hours per week did you train, on average, before COVID-19 confinement? (_)

- How many hours per week did you train, on average, during COVID-19 confinement? (_)

- Did your personal best athletic performance diminish due to the COVID-19 confinement? (Yes, No).

- Do you foresee recovering your athletic performance after the COVID-19 pandemic? (Yes, No).

Individual information, and perceptions and harmful behavioral about COVID-19 crisis. 
- On a scale from $0-10$, how do you evaluate the magnitude of the COVID-19 pandemic today? 0 meaning that you think it is not serious at all and 10 meaning that you think it is extremely serious.

- On a scale from 1-4, were you more stressed (feeling pressured, tense or overwhelmed) than usual because of the confinement? $(1=$ "Not at all" to $4=$ "Extremely affected").

- On a scale from 1-4, how much were you worried about reducing your athletic capability because of the confinement? $(1=$ "Not at all" to $4=$ "Extremely affected").

- On a scale from $1-4$, how worried were you about not being able to participate to sports competitions because of the confinement? $(1=$ "Not at all" to $4=$ “Extremely affected").

- On a scale from 1-4, how worried were you about your financial situation during the confinement?

- On a scale from 1-4, how lonely did you feel during the confinement? (1 = "Not at all" to 4 = "Extremely affected").

- On a scale from 1-4, how much did you miss interacting with other athletes during the confinement? ( 1 = "Not at all" to $4=$ "Extremely affected").

- Have you been tested for COVID-19? (Yes, No).

- Have you been infected by COVID-19? (Yes, No),

- Did you feel more tired than usual during the confinement? (Yes, No).

- Did you have difficulty sleeping during the confinement? (Yes, No).

- Did your food intake/eating change during the confinement? (Eat More than usual, Eat Less than usual, Eat the same as before, no change).

- Did you increase your use of tobacco during the confinement? (Yes, No).

- Did you increase your alcoholic intake during the confinement? (Yes, No).

- Did you take Psychotropic medications for mental health during the confinement (for example; anxiety, depression, panic)? (Yes, No).

- Did you get guidance from your Sports organization about COVID-19? (Yes, No).

- Did you get guidance from your coach about COVID-19? (Yes, No).

- Do you approve of the confinement imposed in your Country? (Yes, No, I'm neutral).

\subsection{Statistical analysis}

The recruited data $(\mathrm{N}=511)$, were grouped on the bases of age $\left(\mathrm{N}_{25 \text { orLess }}=286[56 \%], \mathrm{N}_{26 \text { orMore }}=225[44 \%]\right)$, gender $\left(\mathrm{N}_{\text {male }}=257[50.3 \%], \mathrm{N}_{\text {Female }}=254\right.$ [49.7\%]), academic training $\left(\mathrm{N}_{\text {high school }}=168[32.9 \%], \mathrm{N}_{\text {Professional }}=96[18.8 \%], \mathrm{N}_{\text {Universitary }}=247[48.3 \%]\right)$, Olympic and Paralympic participation $\left(\mathrm{N}_{\text {olympic }}=\right.$ 447 [87.5\%], $\mathrm{N}_{\text {Paralympic }}=64$ [12.5\%]), sport specialty $\left(\mathrm{N}_{\text {Individual }}=328\right.$ [64.2\%], $\left.\mathrm{N}_{\text {Collective }}=183[35.8 \%]\right)$, ranked or with high options to participate in the Tokyo $2021\left(\mathrm{~N}_{\text {Yes_Tokyo }}=261[51.1 \%], \mathrm{N}_{\text {No_Tokyo }}=250[48.9 \%]\right)$.

Before the data analyses, the normal distribution of the dependent variables was tested with the Kolmogorov-Smirnov test. All test results were statistically significant ( $p<.05$ for all tests). Consequently, nonparametric tests were used. Wilcoxon signed-rank test to compare two related samples was used. Group differences in the dependent variables were tested with the nonparametric Mann-Whitney $\mathrm{U}$ test with the Bonferroni correction, which is recommended for smaller samples and might be less sensitive to sample size differences between the groups [15]. To measure the effect size of differences between variables we rely on the following thresholds: small $(|r|=0.1)$, medium $(|r|=0.3)$, large $(|r|=0.5)$, and very large $(|r|=0.7)[16]$.

In case of three groups (i.e. age-groups), the Kruskal-Wallis $\mathrm{H}$ test, also known as the analysis of variance on ranks, was use, calculating the effect size using the epsilon-squared, recommended by Tomczak \& Tomczak [17], giving if we use from Rea \& Parker (1992) their interpretation for r, the following: negligible $\left(\mid \mathrm{E}_{\mathrm{R}}{ }^{2} /=<0.01\right)$, weak $\left(\mid \mathrm{E}_{\mathrm{R}}{ }^{2} /=<0.04\right)$, moderate $\left(\mid \mathrm{E}_{\mathrm{R}}{ }^{2} /=<0.16\right)$, relatively strong $\left(\mid \mathrm{E}_{\mathrm{R}}{ }^{2} /=<0.36\right)$, strong $\left(\mid \mathrm{E}_{\mathrm{R}}{ }^{2} /=<0.64\right)$, and very strong $(|r|=<1)$.

The Chi-Square tests were performed $\left(\mathrm{X}^{2}\right)$ to analyse the ordinal categorical variables related to the Individual, sport and perceptions information about COVID19 crisis.

Additionally, for psychological profile and perceived stress variables a bivariate correlation analysis between all these variables was performed using Spearman's correlation thresholds correlation.

\section{Results}

Table 1 showed the descriptive data such as the number of subjects (N), Mean (M) and Standard deviation (SD) of the age, anthropometric dimensions, training patterns, individual perceptions about COVID-19 crisis and psychological profile. 
Table 1

Age and anthropometric dimensions, training patterns, individual perceptions about COVID-19 crisis and psychological profile (perception of threat and stress).

\begin{tabular}{|c|c|c|c|}
\hline & $N$ & $M$ & $S D$ \\
\hline Age & 511 & 26.28 & 7.94 \\
\hline Body Mass & 495 & 67.86 & 13.83 \\
\hline Height & 503 & 172.92 & 10.28 \\
\hline Training routine disrupted by COVID - 19 & 496 & 3.24 & 0.84 \\
\hline Athletic performance affected by the confinement & 501 & 3.05 & 0.84 \\
\hline Hours per week of training before COVID - 19 & 493 & 17.30 & 9.53 \\
\hline Hours per week of training during COVID - 19 & 494 & 8.44 & 7.16 \\
\hline Gravity of the pandemic & 510 & 7.87 & 1.73 \\
\hline Stressed by the confinement & 501 & 2.57 & 0.89 \\
\hline Worried about reducing the athletic capability & 502 & 2.88 & 0.88 \\
\hline Worried about not being able to participate in competitions & 502 & 3.04 & 0.93 \\
\hline Worried about the financial situation & 499 & 2.49 & 1.07 \\
\hline Feeling lonely during confinement & 502 & 1.78 & 0.87 \\
\hline Miss interacting with other athletes during the confinement & 502 & 3.08 & 0.86 \\
\hline Impact of the pandemic on oneself & 510 & 6.98 & 1.99 \\
\hline Estimation of the duration of the pandemic & 511 & 6.34 & 1.60 \\
\hline Symptoms of COVID - 19 & 509 & 1.44 & 1.18 \\
\hline Concern about the pandemic & 511 & 6.75 & 2.09 \\
\hline Emotional affectation by the pandemic & 511 & 5.69 & 2.40 \\
\hline Affected by unexpected event & 504 & 2.82 & 1.01 \\
\hline Lack of control over important events & 503 & 2.50 & 1.15 \\
\hline Nervous/anxious or stressed & 505 & 2.90 & 1.08 \\
\hline Capable to cope with personal problems & 500 & 3.78 & 1.04 \\
\hline Feel that the events are going well & 502 & 3.63 & 0.87 \\
\hline Incapable to face the responsibilities & 500 & 2.38 & 1.03 \\
\hline Able to manage the problems & 500 & 3.84 & 0.91 \\
\hline Feel in control of all aspects & 501 & 3.05 & 1.10 \\
\hline Angry by events that were out of control & 501 & 2.67 & 1.05 \\
\hline Feel the problems pile up & 498 & 1.98 & 0.99 \\
\hline
\end{tabular}

Applying the Wilcoxon test to compare the number of hours per week that the athletes trained before and during the confinement decreed by the COVID-19, it is observed how the athletes trained more than twice as many hours before $(M=17.30)$ than during confinement $(M=8.44)(Z=-17.291, p<.001$, effect size $[r]=$ 0.78 , very large).

Regarding the age, the $U$ Mann-Whitney test reveal that the group under 26 years of age felt less control of all aspects of life than the group aged 26 and over in the last month $(Z=2.002, p<.045$, effect size $[r]=0.09$, small), athletes under 26 years of age most frequently felt angry / upset due to events that occurred to them that were beyond their control $(Z=2.020, p<.043$, effect size $[r]=0.09$, small $)$ and having a greater feeling that problems pile up that can not overcome them than the group aged $26(Z=1.988, p<.047$, effect size $[r]=0.09$, small). Finally, the group aged 26 and over was more concerned than the group aged 25 and under about their financial situation during the confinement $(Z=3.909, p<.001$, effect size $[r]=0.17$, small), while, inversely, the group aged 25 and under longed for more to be able to interact with other athletes during the confinement $(Z=3.282, p<.001$, effect size $[r]=0.15$, small). On the other hand, the ChiSquare test showed significant differences between the two age groups in relation to whether the athletes approved the confinement imposed in the Country $\left(X^{2}=6.48, p<0.039\right)$ : group under 26 years of age $(Y e s=170,60.3 \% ;$ No $=36,12.7 \%$; Neutral $=76,27 \%)$ and group aged 26 and over $($ Yes $=146,65.2 \% ;$ No $=38$, $17 \%$; Neutral $=40,17.8 \%)$. 
Regarding the gender, the U Mann-Whitney test reveal that female compared to male group affected more emotionally by COVID-19 (e.g. angry, fearful, upset or depressed $)(Z=2.571, p<.010$, effect size $[r]=0.11$, small). Women also perceive that they have been more affected than men by an unexpected event in the last month $(Z=2.668, p<.008$, effect size $[r]=0.12$, small), feeling less control over important events in the life $(Z=4.966, p<.001$, effect size $[r]=0.22$, small), more nervous/anxious or stressed $(Z=5.099, p<.001$, effect size $[r]=0.23$, small), less capable to cope with the personal problems $(Z=2.050$, $p<.040$, effect size $[r]=0.09$, small), less capable to face the responsibilities $(Z=2.728, p<.006$, effect size $[r]=0.12$, small), less control of all aspects of the life $(Z=3.681$, $p$ $<.001$, effect size $[r]=0.16$, small), more angry / upset due to events that occurred that were out of control $(Z=4.442, p<.001$, effect size $[r]=0.20$, small), greater feeling that problems pile up that can not overcome them $(Z=2.941, p<.003$, effect size $[r]=0.13$, small). On the other hand, women disrupted the training routine by COVID-19 more than men $(Z=2.279, p<.023$, effect size $[r]=0.10$, small), feeling also women more stressed (pressured, tense or overwhelmed) than usual because of the confinement $(Z=4.037, p<.001$, effect size $[r]=0.18$, small), more worried about reducing the athletic capability because of the confinement $(Z=3.074, p<.002$, effect size $[r]=0.14$, small $)$ and more lonely during the confinement than men $(Z=2.333$, $p<.020$, effect size $[r]=0.10$, small).

Kruskal-Wallis tests showed that athletes in the group high school evaluated the gravity of the COVID-19 pandemic as less serious than the athletes in the groups professional training and university training $\left(p<.011\right.$, effect size $\left[E_{R}{ }^{2}\right]=0.018$, weak). On the other hand, the athletes in the group professional training saw their athletic performance more affected than the groups of high school and university training by the confinement $\left(p<.001\right.$, effect size $\left[E_{R}{ }^{2}\right]=0.027$, weak), showing the group of athletes with professional training more worried than the group with university training about reducing the athletic capability because of the confinement $\left(p<.021\right.$, effect size $\left[E_{R}{ }^{2}\right]=0.015$, weak), the group with university training more worried in which the group with high school in the financial situation $\left(p<.025\right.$, effect size $\left[E_{R}^{2}\right]=0.015$, weak) and, conversely, the group with high school missed more than the group with university training interacting with other athletes during the confinement $\left(p<.020\right.$, effect size $\left[E_{R}{ }^{2}\right]=0.016$, weak).

Regarding the Olympic or Paralympic participation, the $U$ Mann-Whitney test reveal that in the last month the Paralympic compared to the Olympic athletes felt more capable to cope with the personal problems $(Z=2.593, p<.010$, effect size $[r]=0.12$, small), also more frequently than life events are going well $(Z=$ $1.989, p<.047$, effect size $[r]=0.09$, small) and less lonely during the confinement than Olympic athletes $(Z=2.744, p<.006$, effect size $[r]=0.12$, small). On the other hand, the Chi-Square test showed significant differences between the two types of participation groups in relation to whether the athletes approved the confinement imposed in the Country $\left(X^{2}=10.13, p<0.006\right)$ : Olympic group (Yes $=265,59.9 \%$; No $=71,16.1 \%$; Neutral $\left.=106,24 \%\right)$ and Paralympic group (Yes $=51,79.7 \%$; No $=3,4.7 \%$; Neutral $=10,15.6 \%$ ).

Regarding the sport specialty (individual or collective) the $U$ Mann-Whitney test reveal that in the last month the athletes in individual sports felt more capable of cope with personal problems than athletes in collective sports $(Z=2.596, p<.009$, effect size $[r]=0.12$, small). On the other hand, athletes of collective sports disrupted the training routine by COVID-19 more than athletes of individual sports $(Z=2.716, p<.007$, effect size $[r]=0.12$, small), seeing their athletic performance more affected than in individual sports athletes by the confinement $(Z=1.983, p<.047$, effect size $[r]=0.08$, small $)$ and also more concerned about not being able to participate to sports competitions because of the confinement $(Z=2.012, p<.044$, effect size $[r]=0.09$, small). On the other hand, the Chi-Square test showed significant differences between the two types of sport specialty groups in relation to whether the athletes approved the confinement imposed in the Country $\left(X^{2}=6.10, p<0.047\right)$ : individual sport group (Yes $=192,59.1 \%$; No $=56,17.2 \%$; Neutral $\left.=77,23.7 \%\right)$ and collective sport group $($ Yes $=$ $124,68.6 \%$; No $=18,9.9 \%$; Neutral $=21,5 \%$ ). likewise, the, the Chi-Square test showed significant differences between this groups in relation to in relation to whether the food intake / eating change during the confinement varied $(X 2=8.69, p<0.013)$ : individual sport group (Eat More than usual = 111, 34.6\%; Eat Less than usual $=86,26.8 \%$; Eat the same as before, no change $=124,38.6 \%$ ) and collective sport group (Eat More than usual $=48,26.5 \%$; Eat Less than usual $=71,39.2 \%$; Eat the same as before, no change $=62,34.3 \%$ ).

When applying the U Mann-Whitney no significant differences were observed in any variable analyzed between those athletes ranked or with high options to participate in the Tokyo 2021 and those who had low options.

For the dichotomous questions (answers Yes or No) about the Individual, training patterns and perceptions information about COVID-19 crisis, we present the results in which there have been significant differences when comparing between groups age ( 25 or Less, or 26 or more), gender ( male or female), academic training (high school, professional training or university training), participation (Olympic and Paralympic), sport specialty (individual or collective) and options to participate in the Tokyo 2021 (ranked or with high options or without serious options -low options-). 
Table 2

Perception of threat, stress and training patterns about COVID-19 crisis.

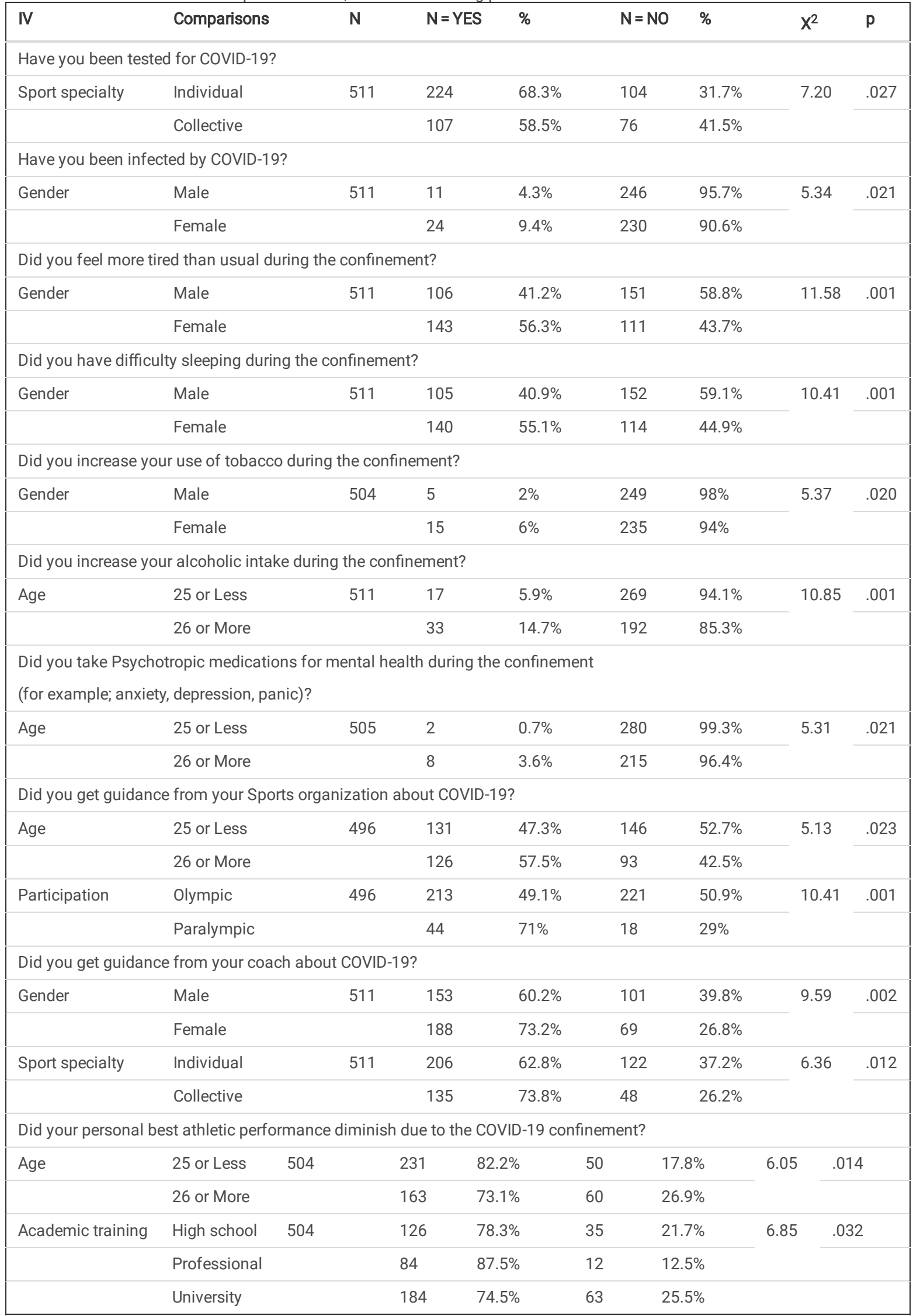

Finally, a correlational analysis of perception of threat, stress and training patterns variables about COVID-19 crisis is shown in Table 3. 
Table 3

Correlational analysis of perception of threat and stress variables.

\begin{tabular}{|c|c|c|c|c|c|c|c|c|c|c|c|c|c|c|}
\hline & 1 & 2 & 3 & 4 & 5 & 6 & 7 & 8 & 9 & 10 & 11 & 12 & 13 & 14 \\
\hline $\begin{array}{l}\text { 1. Impact of the } \\
\text { pandemic on } \\
\text { oneself }\end{array}$ & 1 & & & & & & & & & & & & & \\
\hline $\begin{array}{l}\text { 2. Estimation of } \\
\text { the duration of } \\
\text { the pandemic }\end{array}$ & $.27 \star \star$ & 1 & & & & & & & & & & & & \\
\hline $\begin{array}{l}\text { 3. Symptoms of } \\
\text { COVID }\end{array}$ & .07 & $.11^{\star}$ & 1 & & & & & & & & & & & \\
\hline $\begin{array}{l}\text { 4. Concern about } \\
\text { the pandemic }\end{array}$ & $.40 * \star$ & $.34 * \star$ & $.12^{\star \star}$ & 1 & & & & & & & & & & \\
\hline $\begin{array}{l}\text { 5. Emotional } \\
\text { affectation by } \\
\text { the pandemic }\end{array}$ & $.40 \star \star$ & $.23 \star \star$ & $.13^{\star \star}$ & .51 ** & 1 & & & & & & & & & \\
\hline $\begin{array}{l}\text { 6. Affected by } \\
\text { unexpected } \\
\text { event }\end{array}$ & $.34^{\star \star}$ & $.10^{*}$ & $.12^{\star \star}$ & $.30 * \star$ & $.45^{\star \star}$ & 1 & & & & & & & & \\
\hline $\begin{array}{l}\text { 7. Lack of } \\
\text { control over } \\
\text { important events }\end{array}$ & $.26 \star *$ & .07 & $.10^{*}$ & $.23^{\star \star}$ & $.43^{\star \star}$ & $.53^{\star \star}$ & 1 & & & & & & & \\
\hline $\begin{array}{l}8 . \\
\text { Nervous/anxious } \\
\text { or stressed }\end{array}$ & $.23^{\star \star}$ & $.18^{\star \star}$ & $.11^{\star}$ & $.30 * \star$ & $.50 \star \star$ & $.48^{\star \star}$ & $.54^{\star \star}$ & 1 & & & & & & \\
\hline $\begin{array}{l}\text { 9. Capable to } \\
\text { cope with } \\
\text { personal } \\
\text { problems }\end{array}$ & -.05 & -.06 & $-.10 \star$ & $-.13^{\star \star}$ & $-.23^{\star \star}$ & $-.23^{\star \star}$ & $-.31^{\star \star}$ & $-.30^{\star \star}$ & 1 & & & & & \\
\hline $\begin{array}{l}10 \text { Feel that the } \\
\text { events are going } \\
\text { well }\end{array}$ & $-.14^{\star \star}$ & $-.13^{\star \star}$ & $-.12^{\star \star}$ & $-.15^{\star \star}$ & $-.37 * \star$ & $-.29 \star \star$ & $-.35^{\star \star}$ & $-.34^{\star \star}$ & $-.45^{\star \star}$ & 1 & & & & \\
\hline $\begin{array}{l}\text { 11. Incapable to } \\
\text { face the } \\
\text { responsibilities }\end{array}$ & $.14^{\star \star}$ & .08 & $.15^{\star \star}$ & $.14^{\star \star}$ & $.32^{\star \star}$ & $.40 * \star$ & $.44^{\star \star}$ & $.47^{\star \star}$ & $-.32^{\star *}$ & $-.35^{\star \star}$ & 1 & & & \\
\hline $\begin{array}{l}\text { 12. Able to } \\
\text { manage the } \\
\text { problems }\end{array}$ & -.06 & -.02 & -.08 & --.06 & $-.21^{\star \star}$ & $-.23^{\star \star}$ & $-.36^{\star \star}$ & $-.30^{\star \star}$ & $.52^{\star \star}$ & $.50 \star \star$ & $-.35^{\star \star}$ & 1 & & \\
\hline $\begin{array}{l}\text { 13. Feel in } \\
\text { control of all } \\
\text { aspects }\end{array}$ & $-.14^{\star \star}$ & -.04 & -.03 & $-.12^{\star \star}$ & $-.33^{* *}$ & $-.33^{\star \star}$ & $-.40 \star \star$ & $-.33^{\star *}$ & $.40 * \star$ & $.47^{\star \star}$ & $-.35^{\star \star}$ & $.46^{\star \star}$ & 1 & \\
\hline $\begin{array}{l}\text { 14. Angry by } \\
\text { events that were } \\
\text { out of control }\end{array}$ & $.23^{\star \star}$ & $.11^{\star}$ & .08 & $.20 * \star$ & $.41^{\star \star}$ & $.43^{\star \star}$ & $.44^{\star \star}$ & $.45^{\star \star}$ & $-.26 * *$ & $-.38 \star \star$ & $-.42^{\star \star}$ & $-.23^{\star \star}$ & $-.33^{\star \star}$ & 1 \\
\hline $\begin{array}{l}\text { 15. Feel the } \\
\text { problems pile up }\end{array}$ & $.14^{\star \star}$ & $.16^{\star \star}$ & $.14^{\star \star}$ & $.22^{\star \star}$ & $.40 \star \star$ & $.44^{\star \star}$ & $.49 \star \star$ & $.53^{\star \star}$ & $-.36 * *$ & $-.43^{* *}$ & $48^{\star \star}$ & $-.39 * *$ & $-.35^{\star \star}$ & .55 \\
\hline$M$ & 6.98 & 6.34 & 1.44 & 6.75 & 5.69 & 2.82 & 2.50 & 2.90 & 3.78 & 3.63 & 2.38 & 3.84 & 3.05 & $2 . \epsilon$ \\
\hline$S D$ & 1.99 & 1.60 & 1.18 & 2.09 & 2.40 & 1.01 & 1.15 & 1.08 & 1.04 & 0.87 & 1.03 & 0.91 & 1.10 & 1.C \\
\hline $\mathrm{N}$ & 510 & 511 & 509 & 511 & 511 & 504 & 503 & 505 & 500 & 502 & 500 & 500 & 501 & 50 \\
\hline
\end{tabular}

\section{Discussion}

The aim of the present research was to analyze the effect of age (25 or Less, or 26 or more), gender (male or female), academic training (high school, professional training or university training), participation (Olympic and Paralympic), sport specialty (individual or collective) and high options to participate in the Tokyo 2021 (ranked or with serious options or without serious options) in the individual perceptions about COVID-19 crisis and psychological profile (perception of threat and stress). We found differences in various parameters between the athletes analyzed.

The present situation generated by COVID-19, supposes that people have to adapt to special care to which they are not accustomed and, even, as happened in Spain for more than three months, at the confinement, increased somatization of anxiety, resulting from the perception of lack of control in adapting to contextual demands, existing empirical evidence that emerging adults are at high risk for depression and anxiety related to the psychosocial effects of the COVID-19 pandemic [18]. 
Although the Olympic games are the most important sport event for athletes, and much of then depend on this event for their sports scholarships and sponsorships, there was a high agreement on the suspension of the Tokyo Olympics and the confinement of high-performance athletes (62.5\% in favor, $14.6 \%$ against and $22.9 \%$ neutral), results that are in the same line as the study carried out during confinement by Clemente-Suarez, Fuentes-Garcia, de la Vega, \& Martinez-Patiño [10] also with Olympic and Paralympic athletes. Probably, although the majority of athletes recognize that their best athletic performance diminish due to the COVID-19 confinement (78.2\% Yes and $21.8 \%$ No), with athletes under 26 years of age more negative than group aged 26 and over athletes, on the other hand, the majority of athletes also believe that their athletic performance will recover after the pandemic ( $93.6 \%$ Yes and $6.4 \%$ No). In this sense, the athletes of collective sports disrupted the training routine by COVID-19 more significantly than athletes of individual sports, seeing their athletic performance more affected than in individual sports by the confinement, probably due to the added difficulty of having to meet with more companions in order to train.

The immune landscape in patients with COVID - 19 is considerably different between the sexes, and these differences may underlie heightened disease vulnerability in men (Takahashi, et al., 2020). $64.8 \%$ of the athletes were tested for COVID - 19: $44.8 \%$ with nasal swab and $20 \%$ with antibody (blood) test. $6.8 \%$ declare that they were infected by Covid-19. It should be noted that individual sports athletes underwent a significantly higher number of tests than individual sports athletes and that women presented a significantly higher number of infections than men. These results are not in line with different studies, which have shown that the incidence of coronavirus disease 2019 is higher in males than in females worldwide even though these levels may be influenced by social reasons depending on each country, culture and the specific context in which people find themselves [19].

During confinement, $48.7 \%$ of the athletes declared they were more tired than normal, $47.9 \%$ had difficulty sleeping, $62.9 \%$ eat more (31.7\%) or less (31.3\%) as usual, $4 \%$ increased their tobacco consumption, $9.8 \%$ increased their alcohol consumption and $2 \%$ took psychotropic medications for mental health. Thus these results are in line with other studies in which it has been shown that most individuals are exposed to an unprecedented stressful situation of unknown duration, being a focus of stress, anxiety, fear and depression and also disrupt sleep due to a negative appraisal of the situation and self-protection behaviors $[7,8]$. For all the above, it would be important to teach athletes to manage sleep problems as best as possible during home confinement can limit stress. In relation to the above, during the confinement, the results of our study show that female athletes were significantly more tired than men, with more difficulty sleeping and more tobacco consumption. In relation to the above, the study carried out by Salfi et al. [20] in Italy evaluated through survey sleep quality, insomnia and depression symptoms, perceived stress, and anxiety, showing the female gender the worst condition for all the examined dimensions in both the assessments. Nevertheless, at the follow-up women reported a reduction in insomnia and depression severity symptoms, perceived stress, and anxiety. On the other hand, male participants showed a worsening of sleep quality, insomnia symptoms, and perceived stress. Consequently, the gender prevalence gap of clinical conditions such as insomnia and depression was largely reduced under lockdown, showing women seemed greater long-term resilience during the lockdown, meanwhile, the male gender emerges as the most vulnerable category to the extension of the restraining measures.

On the other hand, the group high school evaluated the gravity of the COVID-19 pandemic as less serious than the athletes in the groups professional training and university training, probably due to less knowledge of the consequences of the situation. The group with university training more worried in which the group with high school in the financial situation, probably because many of the athletes in the latter group are still studying and are more concerned about their training than about work, and, conversely, the group with high school missed more than the group with university training interacting with other athletes during the confinement probably because many of them, being younger, are still giving great importance to forging social relationships.

Regarding the Olympic or Paralympic participation the Paralympic felt more capable to cope with the personal problems, also more frequently than life events are going well and less lonely during the confinement than Olympic athletes. All of the above, probably, by the very fact that disability, in general, and sport for people with disabilities, in particular, somehow prepares these people to better cope with adversity [21].

Something similar could happen regarding the sport specialty, the athletes in individual sports felt more capable of cope with personal problems than athletes in collective sports, where studies such as Sepulveda-Paez, Diaz-Karmelic, \& Ferrer-Urbina [22] show that the relationship between coping strategies and precompetitive anxiety is different between individual sport (swimming) and collective sport (waterpolo), and in this sense, individual sports athletes may be more prepared to face confinement situations.

Faced with all the problems generated by the COVID - 19 previously exposed, 50.3\% of the athletes report that they received guidance from the Sports Federation, with women perceiving this help to a significantly greater extent than men. In part these results could be supported by the fact that women would demand more information from their coach since, also according to our study, that female compared to male group affected more emotionally by Covid-19, more affected by an unexpected event in the last month, feeling less control over important events in the life, more nervous / anxious or stressed, less capable to cope with the personal problems, less capable to face the responsibilities, less control of all aspects of the life, more angry / upset due to events that occurred that were out of control, greater feeling that problems pile up that can not overcome them. In fact, women disrupted the training routine by COVID-19 more than men, feeling also women more stressed (pressured, tense or overwhelmed) than usual because of the confinement, more worried about reducing the athletic capability because of the confinement and more lonely during the confinement than men. These results are in the same line as those of the study carried out by Fuentes-Garcia, Martinez-Patiño, Villafaina, \& Clemente-Suarez [13] with chess players, whose results also showed that women reported a higher level of care to avoid infection than men, and the study of Clemente-Suarez, Fuentes-Garcia, de la Vega, \& Martinez-Patiño [10] also with Olympic and Paralympic athletes, in which that neuroticism and psychological inflexibility was greater in female compared to male group. This is consistent with a previous study [14] in the Spanish population where men and women significantly differed in compliance with safety measures, exercising proper care to wash hands, and in keeping at least $1.5 \mathrm{~m}$ distance from others in public.

On the other hand, in terms of the help received by the coach, 61.8 of athletes perceived that they received help from their coach, with this help being perceived to a greater extent by athletes 25 years of age or younger than those of 26 years of age or older. In this sense, studies such as the one by Navon-Eyal \& Taubman-Ben-Ari [23] have shown that people tended to report difficulties in regulating emotion are younger, with more maladaptive, reckless and careless 
behaviors; angry, hostile and anxious. Thus, it is necessary to reinforce the mechanisms of help and advice from sports institutions to athletes in the face of the pandemic.

Correlation analysis shown how the five items (1 to 5: Impact of the pandemic on oneself, Estimation of the duration of the pandemic, Symptoms of COVID 19, Concern about the pandemic, and Emotional affectation by the pandemic) of the Questionnaire on Perception of Threat from COVID-19 correlate with each other, in most cases strongly, except for the one that deals with the extent to which the athlete feels symptoms due to coronavirus infection (1), which correlates with the other four variables but not It does so with the one that deals with how much the impact of the pandemic affects the athlete (1). On the other hand, all the items ( 1 to 5 ) of the Questionnaire on Perception of Threat from COVID-19 (6 to 15) correlate, practically in all cases strongly, positively with five of the ten items of the Perceived Stress by Psychometric Properties of a European Spanish Version of the Perceived Stress Scale (PSS) (6, 7, 8, 11, 14 and 15: Affected by unexpected event, Lack of control over important events, Nervous /anxious or stressed, Incapable to face the responsibilities, Angry by events that were out of control, and Feel the problems pile up)

The rest of the items $(9,10,12$ and 13: Capable to cope with personal problems, Feel that the events are going well, Able to manage the problems, and Feel in control of all aspects) of the Questionnaire on Perception of Threat from COVID - 19 correlate negatively in most cases strongly with each other and also with the five items of the Questionnaire on Perception of Threat from COVID-19 (1 to 5). Highlight the positive correlation between the item that deals with the athlete's ability to control the problems in his life (12) and the item that deals with the athlete's feeling of controlling the difficulties of his life (13) with the item in question. to the ability of the athlete to cope with personal problems (9) and with the item that refers to the frequency with which the athlete has felt that things are going well (10) and with the item that refers to the disability of the athlete to face the responsibilities (11).

\section{Study limitation and future research lines}

One of the limitations of the study is not having controlled different physiological variables directly, by means of, for example, hormone controls. Another limitation is not having carried out a longitudinal study to observe the evolution of the athletes' perception. These two aspects, on the other hand, are difficult to carry out due to the great difficulty of accessing a large sample of elite athletes. Future research must seek it would be interesting to analyze the impact of COVID-19 crisis in different performance level athletes.

\section{Practical applications}

Considering the results obtained, which reflect, on the one hand, adaptive problems in athletes and, on the other hand, not the sufficient level of support from the institutes against Covid-19, it would be advisable to carry it out on the part of the competent institutions a program to give psychological support to Olympic and Paralympic athletes in which they are taught to face in a way the different psychological problems caused by COVID - 19.

\section{Conclusions}

The situation caused by COVID-19 has had significant effects on the harmful behavioral, perception of threat, stress and training patterns of Olympic and Paralympic athletes facing the 2021 Tokyo Olympiad. These athletes perceived how the pandemic negatively affects their workouts and their best athletic performance, even if it does not affect the recovery of their performance when the pandemic ends. The athletes of collective sports disrupted the training routine and their athletic performance more significantly than athletes of individual sports, finding half of the athletes more tired than normal and with difficulty sleeping. The Paralympic felt more capable to cope with the personal problems during the confinement than Olympic athletes and the athletes in individual sports felt more capable of cope with personal problems than athletes in collective sports. Only slightly more than half of the athletes received guidance from the Sports Federation. Female compared to male group affected more psychologically in numerous variables and disrupted the training routine by COVID-19 more than men.

\section{Declarations}

\section{Ethics Approval, Consent to Participate}

Before participation, experimental procedures were explained to all the participants who gave their voluntary written informed consent to participate in accordance with the Declaration of Helsinki. All the procedures were approved by the Commission of Bioethics and Biosecurity of the University of Extremadura (Spain) (approval number: 57/2020).

The inclusion criteria used for the present research was that athletes were selectable by the corresponding sports federation with options to represent it in Tokyo 2021 Olympic or Paralympic Games.

\section{Consent for Publication}

Not applicable.

\section{Availability of Data and Material}

De-identified raw data are available upon request.

\section{Competing Interests}

None 


\section{Funding}

This study was supported were supported by the Research Project "Investigation of the effect of COVID-19 pandemic on the stress level and mental health of elite athletes", funding by A. James Clark Distinguished Chair of Molecular Genetics, Center for Genetic Medicine Research - Children's National Hospital, Washington, DC, USA (Fund Number 44296), and funding by Centre national de recherche scientifique (CNRS), Paris, France.

\section{Author Contributions Statement}

EV, FJBL and MJMP conceived the study, EV and JPFG supervised the protocol, EV, JPFG, MD and FJBL designed the questionnaire, MJMP and JPFG collected the data, JPFG analyzed the data, MJMP, EV, JPFG, MD and FJBL interpreted the results of the research, JPFG designed Figures and Tables, JPFG wrote the initial draft of the manuscript. MJMP, EV, JPFG, MD and FJBL provided critical edits and revisions and formal analysis on the successive drafts. All authors approved the manuscript in its final form.

\section{Acknowledgements}

Our thanks to the Spanish Olympic Committee and the Spanish Paralympic Committee and to the different Spanish sports federations for their support in the development of this research. We also would like to thank Miguel Almalvez for his work on the references and formatting.

\section{References}

1. Rodriguez-Morales AJ, Katterine Bonilla-Aldana D, Tiwari R, Sah R, Rabaan AA, Dhama K. Covid-19, an emerging coronavirus infection: Current scenario and recent developments - An overview. J Pure Appl Microbiol. 2020;14:5-12.

2. World Health Organization. Coronavirus disease 2019 (COVID-19) situation report -81 [Internet]. 2020. Available from: https://www.who.int/docs/defaultsource/coronaviruse/situation-reports/20200410-sitrep-81-covid-19.pdf?sfvrsn=ca96eb84_2

3. Casadevall A, Pirofski LA. The convalescent sera option for containing COVID-19. J Clin Invest. Am Soc Clin Investig; 2020;130:1545-8.

4. Gobierno de España. The government decrees the state of alarm to face the expansion of coronavirus COVID-19 [Internet]. Available from: https://www.lamoncloa.gob.es/consejodeministros/resumenes/Paginas/2020/14032020_alarma.aspx

5. Gobierno de España. El Gobierno prorroga el estado de alarma hasta el 21 de junio [Internet]. Available from: https://www.lamoncloa.gob.es/consejodeministros/resumenes/Paginas/2020/050620 cministros.aspx

6. Clemente-Suárez VJ, Hormeño-Holgado A, Jiménez M, Benitez-Agudelo JC, Navarro-Jiménez E, Perez-Palencia N, et al. Dynamics of population immunity due to the herd effect in the COVID-19 pandemic. Vaccines. Multidisciplinary Digital Publishing Institute; 2020;8:236.

7. Altena E, Baglioni C, Espie CA, Ellis J, Gavriloff D, Holzinger B, et al. Dealing with sleep problems during home confinement due to the COVID-19 outbreak: Practical recommendations from a task force of the European CBT-I Academy. J Sleep Res. Wiley Online Library; 2020;29:e13052.

8. Li S, Wang Y, Xue J, Zhao N, Zhu T. The impact of covid-19 epidemic declaration on psychological consequences: A study on active weibo users. Int J Environ Res Public Health. Multidisciplinary Digital Publishing Institute; 2020;17:2032.

9. Belinchón-deMiguel P, Ruisoto-Palomera P, Clemente-Suárez VJ. Psychophysiological Stress Response of a Paralympic Athlete During an Ultra-Endurance Event. A Case Study. J Med Syst. Springer; 2019;43:70.

10. Clemente-Suárez VJ, Fuentes-García JP, de la Vega Marcos R, Martínez Patiño MJ. Modulators of the personal and professional threat perception of Olympic athletes in the actual COVID-19 crisis. Front Psychol. Frontiers; 2020;11:1985.

11. Beltrán-Velasco Al, Bellido-Esteban A, Ruisoto-Palomera P, Mendoza KH, Clemente-Suárez VJ. The Effect of Cultural Differences in Psychophysiological Stress Response in High Education Context: A Pilot Study. Appl Psychophysiol Biofeedback. Germany; 2020;45:23-9.

12. McCurry J, Ingle S. Tokyo Olympics postponed to 2021 due to coronavirus pandemic [Internet]. Guard. 2020 [cited 2020 Apr 14]. Available from: https://www.theguardian.com/sport/2020/mar/24/tokyo-olympics-to-be-postponed-to-2021-due-to-coronavirus-pandemic

13. Fuentes-García JP, Martínez Patiño MJ, Villafaina S, Clemente-Suárez VJ. The Effect of COVID-19 Confinement in Behavioral, Psychological, and Training Patterns of Chess Players. Front Psychol. Frontiers Media SA; 2020;11.

14. de la Vega R, Ruíz-Barquín R, Boros S, Szabo A. Could attitudes toward COVID-19 in Spain render men more vulnerable than women? Glob Public Health. Taylor \& Francis; 2020;15:1278-91.

15. Fagerland MW. T-tests, non-parametric tests, and large studiesa paradox of statistical practice? BMC Med Res Methodol. BioMed Central; $2012 ; 12: 1-7$.

16. Fritz CO, Morris PE, Richler JJ. “Effect size estimates: Current use, calculations, and interpretation”: Correction to Fritz et al. (2011). J Exp Psychol Gen. American Psychological Association; 2012;141:30-30. 
17. Tomczak E. The need to report effect size estimates revisited. An overview of some recommended measures of effect size Language and cognition: L2 influence on conceptualization of motion and event construal. View project. Trends Sport Sci [Internet]. 2014;21. Available from:

https://www.researchgate.net/publication/303919832

18. Kujawa A, Green H, Compas BE, Dickey L, Pegg S. Exposure to COVID-19 pandemic stress: Associations with depression and anxiety in emerging adults in the United States. Depress Anxiety. Wiley Online Library; 2020;37:1280-8.

19. Waris A, Ali M, Khan AU, Ali A, Bangash AK, Baset A. COVID-19 incidence in Pakistan: Gender disparity. Iran J Psychiatry Behav Sci. Kowsar; $2020 ; 14$.

20. Salfi F, Lauriola M, Amicucci G, Corigliano D, Viselli L, Tempesta D, et al. Gender-related time course of sleep disturbances and psychological symptoms during the COVID-19 lockdown: A longitudinal study on the Italian population. Neurobiol Stress. Elsevier; 2020;13:100259.

21. Seo E-C, Cho H-J. Testing the Goodness-of-fit of the Scale Representing Satisfaction Level and Comparing Item Difficulty according to Disability Types in Sports-For-All Business for People with Disabilities. J Sport Leis Stud [Internet]. 2016;66:607-20. Available from:

http://www.dbpia.co.kr/Journal/ArticleDetail/NODE07063990

22. Páez GS, Karmelic YD, Urbina RF. Pre-Competitive Anxiety and Sports Coping Strategies, In Individual and Collective Water Sports in High Level Youth Athletes. Límite Rev Filos y Psicol. Universidad de Tarapacá; 2019;16.

23. Navon - Eyal M, Taubman - Ben-Ari O. Can emotion regulation explain the association between age and driving styles? Transp Res Part F Traffic Psychol Behav. Elsevier; 2020;74:439-45. 